\title{
Cleft lip and cleft palate: a disease with multiple risk factors in a pregnant woman
}

\author{
Mustafa Gazi Uçar*, Tolgay Tuyan İlhan, Ayhan Gül, Zekiye Soykan Sert, Çetin Çelik
}

Department of Obstetrics and Gynecology, Faculty of Medicine, Selçuk University, Konya, Turkey

Received: 19 October 2015

Accepted: 18 November 2015

\author{
*Correspondence: \\ Dr. Mustafa Gazi Uçar, \\ E-mail: mustafa_gazi_ucar@hotmail.com
}

Copyright: $\odot$ the author(s), publisher and licensee Medip Academy. This is an open-access article distributed under the terms of the Creative Commons Attribution Non-Commercial License, which permits unrestricted non-commercial use, distribution, and reproduction in any medium, provided the original work is properly cited.

\begin{abstract}
Clefts of the lip and/or palate (CLP) are currently the most common craniofacial birth defects that arise as a result of failure of facial embryonic processes to fuse. CLP etiology, which involves both genetic and environmental factors, is highly complex; its molecular basis remains largely unknown. In the current study we present a case report of a woman with prenatal diagnosis of cleft lip and palate, who had multiple risk factors including genetics, advanced age, family history, antiepileptic drug usage, consanguineous marriage and smoking. Her previous child was born with CLP, and this also contributes. Data of our study supports the hypothesis of a multifactorial etiology for CLP.
\end{abstract}

Keywords: Birth defects, Cleft lip, Oral clefts, Cleft lip and palate, Risk factor, Maternal exposure

\section{INTRODUCTION}

Clefts of the lip and/or palate (CLP) are currently the most common craniofacial birth defects that arise as a result of failure of facial embryonic processes to fuse. These congenital growth diseases can be isolated or associated with other anomalies or part of recognized syndromes. The majority of these orofacial clefts are nonsyndromic.

In general, the types of orofacial clefts are classified into a cleft lip either with or without a cleft palate or a cleft palate only. CLP etiology, which involves both genetic and environmental factors, is highly complex; its molecular basis remains largely unknown. ${ }^{1,2}$ Epidemiological studies on different populations have revealed marked geographical and ethnic differences with the prevalence of disease which is ranging from 1:500 to 1:2500 live births. ${ }^{1-4}$ Disease has a major impact especially on the affected individual, their families and society that needs long rehabilitation between birth and adulthood. The effects on an individual's speech, hearing, appearance, social integration and psychology can lead to long-lasting adverse outcomes for health and wellbeing. ${ }^{4}$
Early referral to a craniofacial clinic is needed to ensure the best outcomes for these children.

Most individuals with CLP require the coordinated care of providers (multidisciplinary care) in many fields of medicine and dentistry. Depending on the location and severity of the cleft, subsequent cosmetic operations may be necessary. Treatment of CLP anomalies is still challenging, costly, lengthy and requires years of specialized care.

In the current study we present a case report of a woman with prenatal diagnosis of cleft lip and palate, who had multiple risk factors.

\section{CASE REPORT}

A 39 year old woman, gravida 3, para 2 at 22 weeks gestation, with a family history of cleft lip and palate was referred to our department for prenatal counseling because of advanced age. A fetal ultrasound with detailed anatomic examination revealed CLP. No other congenital anomalies were observed. After extensive questioning of the patient's medical history, we have learned that her previous child was born with CLP too. Her families have 
a history of clefting, her brother's son who was also born with a CLP. She married her cousin (consanguineous marriage). The patient was diagnosed with epilepsy about 8 years ago and taking regular medication for the last five years. She was receiving carbamazepine $200 \mathrm{mg} 2 \times 1$ pills per day, as well as taking a daily multivitamin supplement with $1.0 \mathrm{mg}$ of folic acid. She has been smoking for 5 years, and also smoked while she was pregnant. She was invited to the high-risk perinatology clinic for routine screening tests and follow-up.

The patient delivered (spontaneous vaginal) a newborn with unilateral cleft lip and palate (figure 1) at 39 weeks' gestation with no complications. No other birth defects and syndromic associations were observed. The newborn infant could not breastfeed, then immediately referred to dentist. Within the first few days after the birth, parents of baby have recieved advices and informed by the surgeon and orthodontist on the immediate and long-term management of their child.

Written informed consent was obtained from the parents of the patients for publication of images.

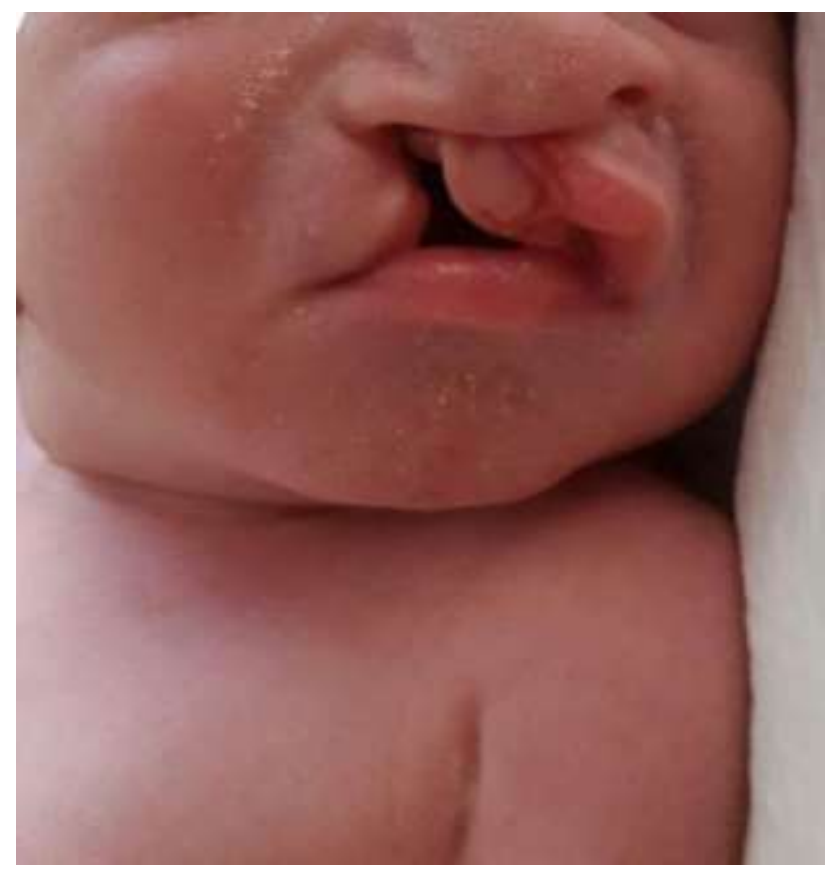

Figure 1: A new born with unilateral cleft lip and palate.

\section{DISCUSSION}

The etiology of CLP is complex but it's thought to be involving interactions of numerous genetic, environmental and prenatal factors. Although the exact cause of CLP is largely unknown, current published evidence shows that there are numerous risk factors that are involved in etiology. Researches indicate that the genes a child inherits from their parents occasionally make them more susceptible to developing a CLP.
Compelling evidences suggest that genetic variants play a substantial role in the development of CLP. ${ }^{5}$ Evidence also shows that the risk of oral clefts among first degree relatives of cases is much higher than that in the general population. ${ }^{6}$

Risk factors such as maternal smoking, maternal age, alcohol consumption, gender, medicinal drugs, viral infection and exposure to teratogens during early pregnancy have previously been investigated. ${ }^{1-7}$ Researchers have proposed some other theories to explain the origin of CLP. Other associated factors are the antiepileptic drugs usage, maternal (toxoplasmosis, rubella, cytomegalovirus, herpes simplex TORCH) infections, nutritional deficiencies (especially folic acid) during pregnancy, and consanguineous marriage between the parents. ${ }^{8}$

Several studies have reported increased risk of oral clefts with increased maternal age at pregnancy. In our study, the mother was 39 years old having her last baby. Although cleft palate without cleft lip is more common in females, the incidence of cleft lip and palates and cleft lips were found to be more common in male than female births. ${ }^{4}$ If the parent or sibling has a CLP, the incidence of disease was significantly increased in subsequent children. Our study showed that familial history of oral cleft was significantly associated with CLP which can imply the role of genetic factors. In this stuty the mother has also a family history and as well as her previous child was born with cleft lip or cleft palate. Her families have a history of clefting, her brother's son who was also born with a CLP. This finding underlines the importance of accurate elucidation of a family history.

It is known that active-passive smoking, lack of folic acid and iron use during pregnancy, maternal age and systemic diseases may play role in inducing cleft formation. ${ }^{7,8}$ She has been smoking for 5 years, and also smoked while she was pregnant.

Older antiepileptics, such as phenytoin, phenobarbital and valproic acid, carry an increased risk for various specific congenital malformations. ${ }^{9}$ It is not yet fully clear whether the use of antiepileptic drugs during pregnancy may increase the risk of CLP. Our patient was diagnosed with epilepsy about 8 years ago and she did not take her anti-epileptic medication in her previous labour. On the other hand, during subsequent pregnancy she has continued to take medication for the whole period. There is disagreement on whether antiepileptic drugs or epilepsy itself are responsible for the congenital malformations found in the infants born to epileptic women who are on antiepileptic treatment. ${ }^{10}$

\section{CONCLUSIONS}

Although CLP is still poorly understood, in this study there are multiple risk factors that contribute to developing a CLP, including genetics, advanced age, 
family history, antiepileptic drug usage, consanguineous marriage and smoking. Her previous child was born with CLP, and this also contributes. Data of our study supports the hypothesis of a multifactorial etiology for CLP, probably involving genetic, environmental and possibly other factors.

Funding: No funding sources Conflict of interest: None declared

Ethical approval: Not Required

\section{REFERENCES}

1. Martelli DR, Coletta RD, Oliveira EA, Swerts MS, Rodrigues LA, Oliveira MC, et al. Association between maternal smoking, gender, and cleft lip and palate. Braz J Otorhinolaryngol. 2015;81:514-9.

2. Rahimov F, Jugessur A, Murray JC. Genetics of nonsyndromicorofacial clefts. Cleft Palate Craniofac J. 2012;49:73-91.

3. Weingärtner J, Lotz K, Fanghänel J, Gedrange T, Bienengräber $V$, Proff $P$. Induction and prevention of cleft lip, alveolus and palate and neural tube defects with special consideration of $\mathrm{B}$ vitamins and the methylation cycle. J Orofac Orthop. 2007;68:266-77.

4. Kelly D, O'Dowd T, Reulbach U. Use of folic acid supplements and risk of cleft lip and palate in infants: a population-based cohort study. Br J Gen Pract. 2012;62:e466-72.
5. Wen Y, Lu Q. Risk prediction models for oral clefts allowing for phenotypic heterogeneity. Front Genet. 2015; $13 ; 6: 264$.

6. Sivertsen A, Wilcox AJ, Skjaerven R, Vindenes HA, Abyholm F, Harville E, et al. Familial risk of oral clefts by morphological type and severity: population based cohort study of first degree relatives. BMJ 2008;23;336:432-4.

7. Taghavi N, Mollaian M, Alizadeh P, Moshref M, Modabernia Sh, Akbarzadeh AR. Orofacial clefts and risk factors in tehran, iran: a case control study. Iran Red Crescent Med J. 2012;14:25-30.

8. Jajja MR, Gilani A, Cawasji ZF, Imran S, Khan MS, Hashmi SS, et al. Oral clefts: a review of the cases and our experience at a single institution. J Pak Med Assoc. 2013;63:1098-102.

9. Holmes LB, Harvey EA, Coull BA, Huntington KB, Khoshbin S, Hayes AM, et al. The teratogenicity of anticonvulsant drugs. N Engl J Med. 2001;344(12):1132-8.

10. Margulis AV, Mitchell AA, Gilboa SM, Werler MM, Mittleman MA, Glynn RJ, et al. Use of topiramate in pregnancy and risk of oral clefts. Am J Obstet Gynecol. 2012;207:405.e1-7.

Cite this article as: Uçar MG, İlhan TT, Gül A, Sert ZS, Çelik C. Cleft lip and cleft palate; a disease with multiple risk factors in a pregnant woman. Int $\mathbf{J}$ Reprod Contracept Obstet Gynecol 2015;4:2044-6. 